\title{
To the memory of Vladimir Stepanovich Shpak
}

On February 23, 2009, Full Member of the Russian Academy of Sciences, Counselor of the Director General of the Russian Scientific Center "Applied Chemistry" Vladimir Stepanovich Shpak passed away at the age of 100.

V. S. Shpak was a prominent scientist in the field of technical chemistry, a pioneer and organizer of studies of new classes of chemical compounds and their application fields as well as development of industrial processes for the production of critical chemicals for special purposes. Under his management and with his direct participation, scientific grounds were developed for the industrial production of aliphatic and aromatic nitro compounds, highmolecular-weight aliphatic amines, functionally substituted esters, and hydrazine derivatives; the most efficient fields of application of these compounds were elucidated and their industrial production was implemented.

For 25 years V. S. Shpak was Director of the State Institute of Applied Chemistry. Works of V. S. Shpak and his staff laid the foundations for the design of new types of defense equipment.

For a long period of time, V. S. Shpak was professor of the Lensovet Leningrad Institute of Technology. Tens of Doctoral and Ph.D Theses were defended under his supervision. He was the author of more than 500 publications and author's certificates for inventions.

Until recently, V. S. Shpak was Deputy Chairman of the Scientific Council on Chemical Sciences in St.-Petersburg, Chairman of the North-Western Division of the Scientific Council of the RAS on Combustion, Vice President of the D. I. Mendeleev Russian Chemical Society, Editor-in-Chief of the Zhurnal Prikladnoi Khimii (Journal of Applied Chemistry).

V. S. Shpak's achievements were marked by awarding him the titles of the Hero of Socialist Labor and Honored Worker of Science and Technology. V. S. Shpak was a winner of the Prize of the RF Government of 2003 in Science and Technology and the Mendeleev Prize. He was awarded the Lenin and Red Banner of Labor Orders and Order of October Revolution.

The blessed memory of Vladimir Stepanovich Shpak will be preserved for ever by his students, friends, and colleagues. 